\title{
Function of Technical English Communication in Business Management
}

\author{
P.Thavabalan, S.Mohan
}

\begin{abstract}
In the techno-connected business world, communication is utilized to preserve a thing or organizations. Exchange communication is characterized as an arrangement of transmitting information and considerations between distinctive parts of an organization conjointly to the people of an outside organization. For any successful organization, communication plays a vital role. Inevitably, business communication in English improves the success rates of any business, and both internal and external communication in English of the organization enhances the profitability. This aim of the paper is to portray the importance of business communication in English, and it is considered to be the soul of success in business.
\end{abstract}

Keywords : Business, Communication, Effective, Soul, Success

\section{INTRODUCTION}

$\mathrm{C}$ reating great business communication aptitudes is as much almost the capacity to create great substance because it is almost a great frame. Business archives must keep up certain benchmarks and ought to be, at most, recognizable globally. Solid Trade Communication aptitudes are basic to the victory of any organization in spite of its measure, topographical area, and its mission. Trade communication is interlaced with the inner culture and outside picture of any organization. It subsequently decides what is communicated, by whom, and at what level within the organization.

\section{METHODOLOGY}

English is presently the worldwide dialect of trade. Increasingly multinational companies are ordering English as the common corporate language. There will be no chance to raise an address that unhindered multilingualism is incapable and can repress critical communications from taking put and get within the way of accomplishing key objectives. The need to immovably facilitate errands and work with clients and accomplices all-inclusive has fast-tracked the move towards English as the official language of business. English has been delegated as the worldwide language of trade and business within the past few eras, influencing numerous key highlights of trade within the show world.

India first appeared on the international stage during an earlier phase of globalization: the era of the steamship and the telegraph [1]. From the outset, India's economic

Revised Manuscript Received on December 20, 2019.

P.Thavabalan *, Research scholar of English, Kalasalingam Academy of Research and Education, Krishnankoil, India. Email: dr.thavabalan@gmail.com

Dr.S.Mohan, Department of English, Kalasalingam Academy of Research and Education, Krishnankoil, India. Email: smohan@klu.ac.in development was thus closely interwoven with a process that has been a powerful driver of the spread of English since the mid-19th century [2]. It is perhaps not surprising, therefore, that even before the present, accelerated phase of globalization, English was perceived in government and business circles to play a crucial role in the functioning of the territory's economy, even though, prior to the 1980s, little was known about the precise nature and extent of English use in the business and professional sectors [3].

It can cross universal borders and go beyond the expectations language compatibility boundaries that have made English the foremost required after language in today's business world. The capability of any language is mainly settled in its success, especially, in the business world. Communicating in English in business environment definitely enlightens its success furthermore.

There are numerous companies; they mostly depend on English for their day-to-day conversation and transaction. Simply saying, their conversations in e-mail, fax, telegram etc., are only in English. It depicts that contemporary business cannot survive without English language.

In the event that we need to purchase or offer a great, we are within the position to communicate with an assorted run of clients, providers, and other business accomplices.

On the off chance that we are talented, they'll share our local language - but we can't tally on it. Companies that all fall flat to define a language procedure are basically restricting their advancement openings to the markets where their language is used, clearly are putting themselves at trouble to competitors that have concurred English-only approaches.

In expansion to this, English has risen as a key language for the fund and the stock markets in this competitive world. Individuals who wish to begin the business universally got to have a great get a handle on of Business Communication. The capacity to clearly type in English is additionally a key, as numerous shapes of trade communication, from emails to presentations and showcasing to critical commerce bonds, are showcased in English. An online site that has been composed in English can pull in numerous clients and encourage little commerce proprietors indeed in farther towns to offer things to individuals around the world. Well-written item and benefit portrayals in English are the key variables for drawing in modern clients and keeping them up to date on any unused items offerings.

The fastest-spreading language in human history, English is spoken at a useful level by some 1.75 billion people worldwide - that's one in every four of us. There are close to 385 million native speakers in countries like the U.S. and Australia, about a billion fluent speakers in formerly 
colonized nations such as India and Nigeria, and millions of people around the world who've studied it as a second language. An estimated 565 million people use it on the internet.

According to Crystal, Peters, and Graddol about 80 per cent of the world's trade and financial business is transacted in the English language. Hence, enterprises worldwide have noted the necessity of having a workforce that is able to communicate in English if they are to take advantage of the opportunities in the global marketplace [4].

In case organizations are to outlive and succeed within the quickly changing worldwide environment, they must persistently alter the way communication forms are organized and conveyed. This worldwide environment powers us to think almost communication issues against the scenery of culture, innovation and competition, which ceaselessly raise legitimate and moral concerns[5]. In any organization, communication plays a pivotal part in the employer-employee relationship. It gives a making a difference hand in communicating goals, necessities, feelings etc.

\section{RESULTS}

A compelling communication must have certain capacities which have been portrayed below:

- Completeness

- Conciseness

- Consideration

- Correctness

- Courtesy

- Clarity

- Concreteness

Channels of business communication are listed below:

- Web-based Communication

- Emails

- Writing letters, reports, memos etc.

- Video conferencing

- Audio \& video presentation

- Using telephone

- Face to face meetings

Trade communication is somewhat distinctive and interesting from other sorts of communication, as the point of trade is to win cash. Hence, to create productivity, the communicator ought to improve their great communication aptitudes [6]. Knowing the significance of communication, numerous associations prepare their representatives in communication abilities.

Adopting a global language policy is not easy, and companies invariably stumble along the way. It's radical, and it's almost certain to meet with staunch resistance from employees. Many may feel at a disadvantage if their English isn't as good as others', team dynamics and performance can suffer, and national pride can get in the way.[7] But to survive and thrive in a global economy, companies must overcome language barriers - and English will almost always be the common ground, at least for now.

In the past three decades, the status and functions of English in the professional world in India have been influenced by two apparently divergent forces: globalization and decolonization[8]. Whereas the former, the increasing interdependence and integration of economies and economic activity, would point to a significant expansion in the role of a language which is at the heart of many globalization mechanisms [9].

The impact of Business Communication and its principles towards the Success in Business have been projected in the given picture $1 \& 2$ :
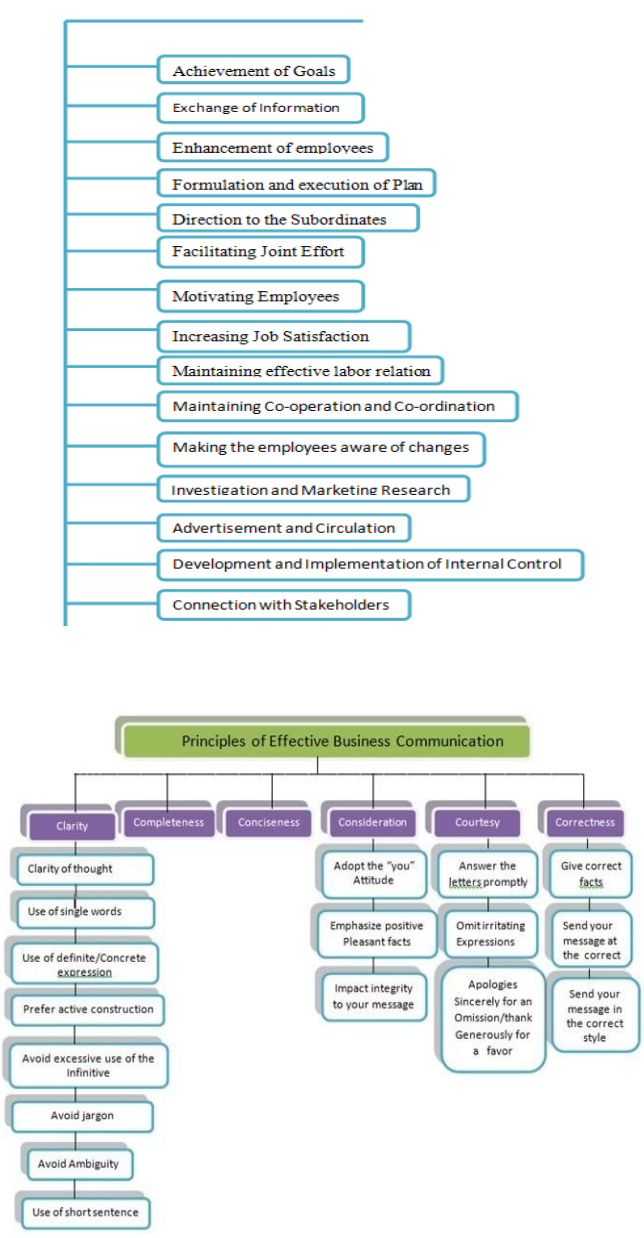

IV. CONCLUSION

From the above statements, it is understood that success in any business definitely depends on the way how the businessmen convincingly communicate with their clients. Without a doubt, English in business communication significantly improves the success rate of any business. Most of the successful businesses have achieved its current position only because of its effective communication in English. Considering all these points, it is come to conclude that English in business communication functions as a Soul of Success in the Global Market. 
A further quantitative and qualitative study on this area will definitely paves way to the future researchers.

\section{REFERENCES}

1. Newman, Amy, and Scott Ober. Business Communication: In Person, In Print, Online. 8th ed. Mason: South-Western, 2013. 18.

2. Easton, Anna; Heidewald, Jeanette; Morrone, Michael; Neher, Darryl; Steiner-Williams, Judy. Strategic Business Writing (2nd ed.). Trustees of Indiana University. p. 21. ISBN 978-0-253-01611-9.

3. Downs, C.W and Hazen, M.D (1977). A Factor Analytic Studyof Communication Satisfaction. Journal of Business Communication, 14:3pp. 63-73.

4. Crystal, D. (1997). English as a global language. Cambridge: CUP.

5. Graddol,D.(2008). English Next: "Why global English may means that HB the end of English as a foreign language." ULIS.

6. Durant, A.and Shepherd,I. (2009). 'Culture' and 'communication' in intercultural communication. European Journal of English Studies, Vol. 13, No. 2, August 2009, pp.147-162.

7. Peters, P.(2004). The Cambridge guide to English usage. Cambridge: Cambridge University Press.

8. Fay, M.J (2011). Informal communication of co-workers: a thematic analysis of messages. Qualitative Research in Organizations and Management: AnInternational Journal, Vol. 6 Iss: 3 pp. 212-229.

9. Marques, J.F (2010). Enhancing the quality of organizational communication: A presentation of reflection-based criteria. Journal of Communication Management, Vol. 14 Iss: 1 pp. 47-58.

10. https://www.businesscommunicationarticles.com/importance-of-comm unication-in-business/

11. http://www.businessdictionary.com/definition/effective-communicatio n.html.

\section{AUTHORS PROFILE}

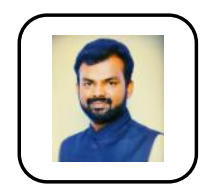

Mr.P.Thavabalan was born in Madurai, India, in 1991. He received B.A M.A.and M.PHIL degrees in English Literature from Madurai Kamaraj University, Madurai, India, respectively in2009, 2012 and 2015. He has been working as Assistant Professor in the Department of English, Kalasalingam University for 3 years. He has been teaching to the students of Engineering and Arts and Humanities. His research interest is English Language Teaching and Business Communication, Indian Writing in English, Comparative literature. He is a Member of ELTAI.

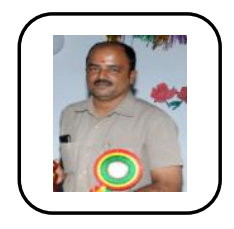

Dr.S.Mohan has been serving as an Associate professor of English. His area of specialization is English Language Teaching and African -American Literature. He is serving as the chief Editor of an International Journal and Editorial Board member for Eight International Journals. He has published fourteen research articles in different journals. He also Guided 26 M.Phil scholars and guiding $\mathrm{PhD}$ candidates. He is a life member of International Association for Academicians and Researchers, Donor member of ELTA. 